\title{
Distance Education and Self-Study
}

\author{
Barrie W. Jones \\ The Open University, Milton Keynes MK7 6AA, United Kingdom, \\ B.W.Jones@open.ac.uk
}

\begin{abstract}
Distance education and self-study are defined and described and their possible application to developing countries is discussed.
\end{abstract}

\section{Introduction}

It is not my purpose to specify how distance education and self-study should be used to teach astronomy in developing countries - my teaching experience in such countries, though not negligible, is rather too limited for that. I do, however, have extensive experience of distance education in the U.K., and therefore my purpose in this article is to display the characteristics of distance education, and of self-study, in order to promote debate about how they can best be used in astronomy education in the developing world. Distance education has the potential to overcome

- a shortage of astronomy teachers

- a shortage of non-human resourses

- difficulties that students face in attending a campus.

Additionally, distance education materials can be used to increase self-study on campus, and hence overcome the first two of these problems.

\section{What is Distance Learning(and Self-Study)?}

The main defining characteristics of distance education are that

- it allows students to study at home or in their work place

- it allows students to study part-time or full-time

- course materials are delivered to students mainly by mail, or electronically

- face-to-face contact with a teacher is limited, even absent.

Face-to-face contact with other students can be less limited, particularly in urban areas, if several students of a course live or work near each other. 
Self-study is that aspect of any learning process where students study on their own, i.e. without real-time human contact. In distance education, selfstudy accounts for a far larger proportion of the student's study time than it does in conventional education. However, it is vital to realise that if distance education is to be effective then the student must be supported - sending out materials and letting the student get on with it is a recipe for failure. Forms of support include

- preliminary advice to the student about which courses best match the student's needs, and in what order the courses should be taken

- a clear specification to the student of the knowledge and skills that the student should bring to each course

- course materials (printed or electronic) that are suitable for self-study

- a clear study guide for each course, with a study timetable, including assignments to be completed at specified times throughout the course

- a personal tutor, in telephone, e-mail, mail or (limited) face-to-face contact, who also marks the student's assignments, but as well as grading them, provides copious teaching comments on them

- student self-help groups, with telephone, e-mail or face-to-face contact

- residential schools in mid-course, with a focus on practical work in science (just a few days a year is of enormous benefit).

Even with all of these forms of support, distance education is not easy for teachers or for students. The students need to be motivated and determined, and the tutor needs to acquire the special skills needed to teach in this way. But distance education provides the possibility of education where otherwise there would be none.

At its best, distance education can provide an education as good as any obtained by conventional means. Experience in the U.K. and elsewhere is that any scepticism about whether this is an effective way to teach science in general and astronomy in particular, is completely unfounded.

\section{Distance Education in Science around the World}

Distance education is rapidly spreading, in developing and developed countries. It is almost entirely targeted at students at least 18 years of age, and therefore distance-teaching is mainly through universities and colleges, rather than schools. But the level of courses and qualifications need not be at degree level, and indeed many are not.

Increasing numbers of conventional institutions are offering the option of distance education, though this is often a rather small part of their activities. In addition there are institutions dedicated to distance education, and many of these are national bodies. The first large national institution was the U.K. 
Open University (UKOU), which admitted its first students in 1971. It now has about 170,000 students. The majority are studying for undergraduate degrees, but some are aiming for masters' degrees, and others are not aiming to get degrees at all. The countries with the largest national institutions include (in alphabetical order)

$\begin{array}{ll}\text { China } & \text { France } \\ \text { India } & \text { Indonesia } \\ \text { Korea } & \text { South Africa } \\ \text { Spain } & \text { Thailand } \\ \text { Turkey } & \text { U.K. }\end{array}$

Among the national institutions worldwide, few teach science of any sort, and even fewer teach astronomy. Therefore, there is a great opportunity for expansion, though it will be necessary to convince the institutions and potential students of the value of an astronomy education, not just the cultural value, but particularly the economic value arising from the wide range of scientific and other skills that are well taught through astronomy. Astronomy need not be taught on its own. It can be included within science courses where it acts as an attractor of students, as a motivator, and as a rich source of fascinating examples. This builds the case for astronomy to be taught in places where, on its own, it might be seen as lacking relevance to the needs of a developing country.

Another argument for distance education in developing countries is the experience of many institutions that the total cost of producing a graduate by distance teaching is roughly half the cost of producing a graduate by conventional means. This reduction in costs is achieved when at least several hundred students enrol for a particular course.

An important type of student is the school teacher; distance education has enormous potential to increase the number of teachers in a developing country who are willing and able to teach astronomy in their schools. From such grassroots teaching, much can grow.

\section{The Production of Effective Distance-Learning Courses}

I address here the preparation of a course rather than a complete degree programme. In the UKOU a course can typically account for anything from about $3 \%$ of a degree to about $18 \%$; these are 10 -point and 60 -point courses respectively. Students are free to take just a single course, for which they are awarded a certificate of completion.

\subsection{The course team}

At the heart of course preparation is the course team, and experience worldwide has shown that this is the single most important way of achieving quality and effectiveness in a course. The success of the course team approach rests in the discussions that define the course structure and content, and on the comments that an author receives from several others on the first and subsequent drafts of any material (s)he produces. 
For all but the shortest courses at the UKOU, a typical course team has the following membership

- four to six academics, one of whom chairs the course team; they are responsible for the academic design and structure of the course, and they either produce all drafts of all the academic material (printed and any electronic material), or produce the final draft of material provided by consultants

- a course manager, who is responsible for the day-to-day running of the team, and who liaises between the team and the various design and production agencies for the course material

- an editor, who puts the final gloss on printed materials, e.g. by checking for consistency and by advising on literary style

- various other people depending on the course components, e.g. a TV producer if there is any TV or video, a software expert if there are any CD-ROMs or internet usage.

The course team might use consultants to prepare first drafts of certain materials, and there should always be one or more external subject experts and education experts to comment on the drafts.

It is possible for an astronomy course, or a science course with an astronomy content, to be prepared or adapted by a course team with rather few members from a developing country. This is important given the shortage of astronomy educators in some countries. But at the very least there should be one academic from the developing country, otherwise the course might not be shaped to serve the students' or the country's particular needs.

\subsection{Course components}

A common misconception about distance learning is that electronic media are the chief conveyors of course content. This is unlikely to be the case even with the emerging e-university approach (see below), and it is certainly not the case at the moment. Printed texts typically carry most of the course material.

Electronic media, which include videos, CD-ROMs, and broadcast TV, are very good for certain teaching functions, but unless they already exist they can be expensive to produce, particularly CD-ROMs. These media also require the student to have access to the appropriate equipment.

In science, and notably in astronomy, a course component of great value is a kit of very simple items for practical work. Indeed, the 'kit' here need be nothing more than a list of items that a student can readily obtain. There must, of course, always be a clear description of how the practical work is to be carried out. At the UKOU we have found that high-order skills can be developed in this way, e.g. recording relevant details, tabulating data, graph plotting, analysis of results including estimating uncertainties, report writing. Successful practical projects for which we have sent out no equipment have included measuring the length of the sidereal day, a quantitative study of light pollution, measuring the luminosity of the Sun, and many more.

An essential feature is some sort of interaction with a tutor - more on this in the next section. In addition, a residential school of up to a week, with a focus 
on practical work, is of enormous benefit, but can be expensive to set up, and it might be unfeasible for students to travel to it. However, if it is a requirement of course accreditation that there is supervised practical work then a residential school will be essential, and it will almost certainly be more feasible to have a single, week-long school than, say, three week-end schools.

\subsection{Active learning}

It almost goes without saying that the course materials must build on prerequisite skills and knowledge that are clear to the author and to the student. But even when a student comes to a course adequately prepared, it is essential that the course encourages the student to engage in active learning.

One feature of active learning is in one's approach to reading a text - we attempt to teach active learning skills such as note-taking, highlighting, and summarising. Another feature of active learning is to test whether what has been studied has been understood. This must not only involve recall, but the application of knowledge and skills in situations that are new.

UKOU science materials typically include three types of active-learning selftest. First, there is the 'stop-and-think' device. This is a short question, clearly delineated, and placed at any point in a text (print or electronic). It tests whether the student has understood the immediately preceding material. It can do this by requiring recall, or a simple application, or that the student continues the 'story'. The correct response immediately follows the question.

Second, there are questions placed at the ends of sections. These test understanding of a greater span of material. A full, acceptable response is always given (usually at the back of a text), along with comments that can be extensive. Third, there is a longer piece of work, often called an 'activity'. There are fewer of these than of the questions. Examples include summarising an extended piece of material, solving an extended problem, carrying out a practical investigation, building a conceptual model. Acceptable responses plus comments are again normally included at the end of the text.

We design science courses so that if an average student does all the self-tests (as they are strongly encouraged to do), then about $25 \%$ of the total study time will have been spent on them. Time spent on assignments that are graded by the tutor is additional to this.

Most textbooks are rather weak on active learning. End-of-chapter questions are often about as far as it goes, and it is common to get just a single number as an answer to a numerical question, and no answer at all to other questions. Some UKOU science courses do however use textbooks at the higher levels of study, along with a specially prepared study guide that, among other things, provides an opportunity for active learning.

\section{The Effective Delivery of Distance-Learning Courses}

As much care needs to go into the delivery of a distance learning course as into its production, otherwise many students will not complete the course who otherwise would have done. The academic aspects of delivery are in the hands of a presentation course team, much smaller than the production course team. 
The first requirement (as mentioned above) is that prerequisite skills and knowledge must be specified to the student beforehand, and the course must be built only on these. Among the skills are those for the self-study that is at the heart of distance learning; these study-skills need either to be specified for entry, or they need to be taught within a course. They include

- time planning

- active reading (notetaking, highlighting, summarising)

- dealing with difficult material (including how not to get unduly 'hung up')

- written communication (including essay writing, but other forms too)

- problem solving, mathematical and otherwise.

To assist students with time planning there must be assignments throughout the course. These will be prepared by the course team, new ones for each presentation of the course. The student has to send the completed assignments to the tutor by clear deadlines. In the UKOU a course lasting nine months will have at least four such deadlines, roughly equally spaced. There will then be an end-of-course examination. The UKOU assignments are graded by a tutor, and the overall grade, along with the examination mark determines the student's course grade. This gives the student a strong incentive to meet the assignment deadlines!

\subsection{Tutors}

Tutors have a crucial role to play in raising the quality of course delivery. In the UKOU a tutor of a course will have about 20 students, though this number could be increased.

The tutor, by writing clear and copious comments on the student's assignments, targeted at the student's individual needs, thereby carries out an important teaching function. The UKOU physics and astronomy courses have been much praised in the recent round of external review of university teaching for this aspect of tuition. The tutor also has an important teaching function through other forms of contact. There might be a few hours of face-to-face tutorials, but more extensive contact is usually by telephone, and increasingly by e-mail.

Tutors must clearly be trained to help deliver a distance-education course, not only in their general role, but also sometimes in the subject they are tutoring. In the UKOU, tutoring a single course, even a 60 point course, is a part-time job, so most of our tutors have full-time jobs in universities or in schools. We have found that for the more introductory science courses, teachers of senior-school science make admirable tutors.

Some of the tutors of our introductory astronomy course initially had very little knowledge of astronomy - many had backgrounds in physics or in geology. Therefore, in developing countries, the shortage of astronomers to act as tutors for an introductory astronomy course might not be a major problem, provided there are adequate numbers of willing senior school science teachers. 


\subsection{Completing the feedback loop}

To achieve high quality it is essential that there are systems that encourage feedback from tutors and students to the presentation course team, and it is equally essential that the course team takes swift and appropriate action. Errata in course materials, problems with assignments and with the examination, can then be put right for the current cohort of students. It might only be possible to correct other problems, such as a course being overloaded or out of date, in time for the following cohort, but without feedback some problems are unlikely to be corrected at all.

About every four years a course should be thoroughly reviewed by subject experts, to see if any updating is required. The course team should also look out for opportunities to use new media, notably electronic media.

\section{The e-University}

An e-university is one that relies on the Internet for a substantial proportion of its teaching operations. An e-university need not necessarily be a distance teaching institution, but many distance teaching institutions are moving in the direction of becoming e-universities. Quite at what point the UKOU could be called an e-university is a matter for a not very relevant discussion; some say that it is already an e-university.

An e-university offers great promise because it could enable students in any country to study the distance-learning courses of an institution in another country. The drawback is that the student needs ready access to the Internet.

It is sometimes claimed that all aspects of study should ultimately be handled over the Internet. This is not a desirable goal; there are things for which the Internet is not the most appropriate medium. These include

- anything that could as well be on a CD-ROM

- long texts

- the end-of-course examination.

Let us look at each of these in turn.

Unlike the Internet, a CD-ROM is not subject to slow telephone lines and to loss of connection. Regarding long texts, there are problems with reading from a screen for long periods, and only to be able to access most of a course via the Internet is quite a restriction on flexibility of study. It is not proper to suggest that the student overcomes this problem by printing out the text - this would load huge costs for colour printing on to the student.

An end-of-course examination needs to be such that the resulting student award is credible. Therefore, some form of invigilation is required, and so a credited invigilator would have to be present throughout the examination. It would be impractical for an invigilator to travel to a single student's home or place of work, and so, to use the Internet, there would have to be a sizeable group of students in a room equipped with many terminals, and the invigilator would have to be able to ensure that each student was not getting inappropriate 
help from the Internet. This could well be impractical and so a conventional examination would then be required.

Appropriate uses of the Internet include

- information on a course

- registration for a course

- delivery of assignments by the course team to the student; delivery of completed assignments by the student to the tutor; the return by the tutor to the student of the assignment grade and teaching comments

- e-mail between student and tutor and between students, including 'noticeboard' discussions

- delivery by the course team to the student of errata, stop-presses, updates, and other news

- feedback between the course team, the students, and the tutors

- guided use of databases

- use of robotic telescopes

- use of on-line journals.

The issue of the credibility of an award does not arise in relation to the assignments provided that the award system requires threshold performances in the assignments and separately in the end-of-course examination.

Clearly an e-university could bring astronomy education to a developing country, provided that the problem of Internet access can be solved, and provided that conventional invigilation for examinations can be provided.

\section{Self-Study of Astromony on Campus}

Course materials designed for distance education can be used to great effect on campus to alleviate a shortage of astronomy teachers and a shortage of nonhuman resources. This is because self-study reduces the number of contact hours required for a learning outcome, and because certain distance education materials can reduce the need for high cost resources, e.g. laboratory space. It is however essential for the student to be acculturated to the use of self-study for acquiring core content.

Such contact hours as are available can be used for higher quality forms of contact, such as

- inspirational lectures (rather than lectures to deliver core content)

- problem-solving classes

- small-group tutorials. 
All in all, it is my view that distance education has considerable potential for extending the teaching of astronomy in developing countries on campus as well as off it.

\section{Discussion}

Dworetsky asked if the costs quoted were the full costs or only the fee charged. Jones replied that the figure he gave (approximately $50 \%$ of the cost of producing a graudate by conventional means) included all costs. Gerbaldi, speaking from her own experience of distance-education commented that costs should not be reduced too far since distance-learning is much more effective when there is an on-line tutor (working through e-mail). She also felt that a tutor was needed if students were using distance-education material on a conventional campus. Finally, she pointed out that methods of learning differ from country to country for both cultural and political reasons. There is need for caution in extending the use of distance-learning to some countries. In reply, Jones reiterated that his $50 \%$ figure included provision for a tutor. He agreed that students using distance-education materials on campus needed some tutorial help, but it is also important to acculturate students to self-study. He agreed that cultural and political problems could arise in the use of distance education in some countries. In fact, many of the U.K. Open-University materials had been used successfully in a variety of countries. More experience is needed, especially in astronomy, and might lead to the production of several versions of a course, to take account of local conditions.

Orchiston mentioned that the Swinburne University of Technology in Melbourne and the University of Western Sydney now offer courses in astronomy. It is possible to take adult-education courses that lead to both bachelor's and master's degrees in astronomy. Jones replied that he had not discussed adulteducation courses on campus, although they are certainly an important means of offering astronomy to a wider public. The University of Central Queensland used to offer distance education, but he was not sure if it still did so.

Pasachoff commented that, in the U.S.A., several venture capitalists are funding major on-line courses. He is most familiar with GEN, the Global Educational Network, which is now putting together some dozens of courses in a wide variety of fields, which will be delivered over streaming video (this apparently saves some copyright expenses compared with providing images on CD-ROM or the Web, since legally no copies are being made. They hope to sell these courses for $\$ 300-\$ 600$ apiece, not mainly to traditional $18-22$ year-old University students but, rather, to advanced-placement high-school students or alumni some years or decades past graduation.

He also commented on Jones's remark that on-line courses free academics for higher-level work. Pasachoff felt that that requires good faith on the part of the institution. It is all too possible that once a course is on tape, or on the Web, staff could be made redundant or not rehired, or that the steady-state of faculty and staff could be lower than it otherwise was. He knew of at least one faculty union was wary of the faculty tape-recording courses for a remote campus, because of the possibility that the faculty member would not be rehired. 
He also asked how much a single course cost at the Open University? Jones replied that a full degree, three or four years' worth of courses, is about $£ 3900$ pounds. The fee to a student for a single course $£ 300$, which is probably about half the total cost to the Open University. The figures are roughly comparable to those quoted by Pasachoff. 